Available for free online at https://ojs.hh.se/

JISTB

Journal of Intelligence Studies in Business 3 (2012) 41-47

\title{
Applying Competitive Intelligence: The Case of Thermoplastics Elastomers
}

\author{
Marisela Rodriguez Salvador* and Luis Francisco Salinas Casanova** \\ *Instituto Tecnológico y de Estudios Superiores de Monterrey (ITESM), \\ **Exa-tec Campus Monterrey, Mexico \\ marisrod@itesm.mx and 00casanova@gmail.com
}

Received February 2, revised form May 20, accepted December 182012

\begin{abstract}
The objective of this article is to investigate and identify drivers to compete in the industry of plastics through the application of the methodology of Competitive Intelligence. Practical implications: This article provides a practical case of the Competitive Intelligence Methodology applied to the Thermoplastics Elastomers Industry, specifically within the Styrenic Block Copolymers category. The output of this research helped support a Mexican Company in their decision-making process.
\end{abstract}

KEYWORDS: Competitive Intelligence, Thermoplastics Elastomers, Styrenic Block Copolymers, Hydrogenated Styrenic Block Copolymers

\section{Introduction}

Thermoplastics Elastomers (TE) are a class of polymers with rubber-elastic behavior and a processing system typical of thermoplastics. TE has the property of being reprocessed when heated above the melting temperature. The capacity of being reused is an advantage regarding the limitation of recycling thermoset rubbers, and with little waste when processing. Moreover, TE provides significant benefits to reduce pollution impact in the environment, and it has an important role in the economic aspect.
Styrenic Block Copolymers (SBC) are high performance Thermoplastics Elastomers designed to improve a wide range of products and applications. The SBC consist of at least three blocks, two of them are hard polystyrene blocks and one a middle block soft (polybutadiene or polyisoprene); they may or not be hydrogenated. (Nandini Consultancy Center, 2011).

The Asian continent has now become the main market for SBC, due to a great demand from China. The country is the largest producer of footwear in the world, followed by India; both 
consume large quantities of rubber and elastomers, including SBC (Löchne \& Mori, 2011). However the current overcapacity of SBC's in manufacturing plants in China has caused this product to become a commodity for other uses. The industry presents (Löchne \& Mori, 2011):

- A high volatility of raw materials (butadiene, isoprene and styrene);

- Overcapacity production in China.

- Some effects from the global economic crisis of 2008-2009;

Under this context the main goal of this research is to identify new opportunities to compete in the industry of Thermoplastic Elastomers (TE) in the category of "Styrenic Block Copolymers (SBC)", through the application of the methodology of Competitive Intelligence. The main aim is to identify opportunities to exploit.

The research started with the interest of the authors in the Competitive Intelligence field and in particular how this facilitates the process of decision-making to innovate. It was decided to implement the method in the case of Thermoplastic Elastomers as a part of a CONACYT (National Council of Science and Technology) project between a Mexican Company (for confidentiality reasons for now the company will be called "XYZ"), and the Competitive Intelligence Unit of the Center of Quality and Manufacturing at Tecnológico de Monterrey (Tec), Campus Monterrey.

\section{Competitive Intelligence Methodology}

As Kahaner (1997, p. 16) established Competitive Intelligence $(\mathrm{CI})$ is "a systematic program to collect and analyze information about competitors' activities and general business trends to achieve the goals of the company". Moreover, CI comprises identification of intelligence needs within an organization, collection of data from primary and secondary sources, evaluation and analysis. The main objective is to provide information for the decision making process in order to add value to the organization.
The basic model that the CI methodology follows involves a Cycle where Intelligence can be viewed as a process and as a product - the intelligent result - (Bose, 2008). The following figure shows an adaptation of the approach proposed by Murphy (2005):

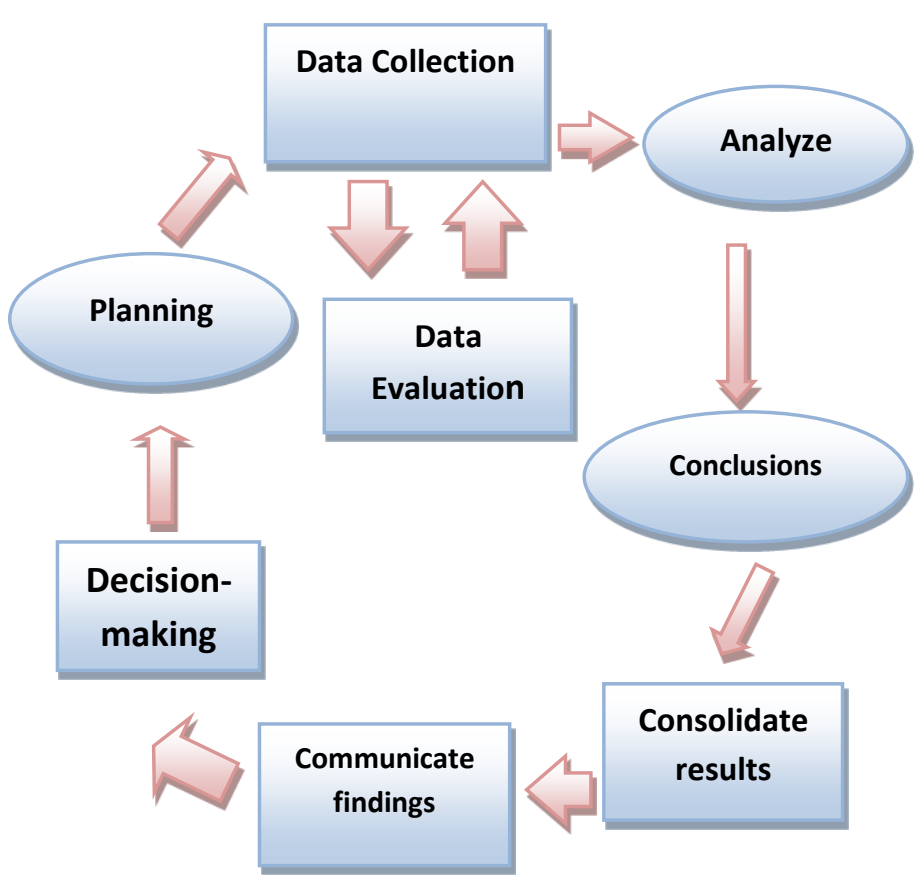

Figure 1: Competitive Intelligence Model (Compiled from Murphy, 2005)

The principal objective of this model is to support innovation. Innovation involves a process to create new knowledge and ideas in order to achieve improvements in processes and organizational structures, creating new products and services focused on market's needs (Bareghehs, 2007) and (Rowley, \& Sambrook, 2009). Moreover, innovation could be seen as the implementation of ideas to create value (Patterson 2009 in Vega, 2010). From this perspective CI is a valuable methodology that helps companies to generate those ideas that are important for the company, searching and analyzing key pieces of information from the competitive environment of the organization. 


\section{The case of study: Thermoplastics Elastomers.}

As we mentioned earlier, this research was developed to analyze the Thermoplastics Elastomers industry. The scientific method was applied during this research as part of a master thesis entitled "Application of Competitive Intelligence Methodology: Case of Thermoplastic Elastomers" written by Luis Salinas. It was developed for the Engineering School of Tecnológico de Monterrey, Campus Monterrey.

The objectives pursued were: contribute to increase the practice of CI methodology in Mexico; identify market growth rates in this industry; identify lead competitors; to finally support the strategic planning of the company "XYZ" based on the evidences obtained. For this purpose we followed the model proposed by Murphy (2005) as it is explained in next paragraphs.

\section{Definition of the Initial Problem}

The first stage in the process was to define the problem, in this initial phase the company "XYZ" expressed their intelligence needs personally. The company pursued to obtain relevant information regarding new market opportunities or new applications aligned to their core business, in this case the Thermoplastic Elastomers.

2. Identification of the Key Intelligence Topics (KIT's)

During this phase of the process, the following KIT's were defined to start the research activity:

- Thermoplastic Elastomers

- Styrenic Block Copolymers

- Styrene Block Copolymers

3. Initial Review of the Literature

A deep revision of literature on the subject of Thermoplastic Elastomers was conducted. This activity was complemented with interviews with industry experts. This stage was useful to build a theoretical framework for this research.

\section{Preliminary Identification of Information Sources}

After reviewing the literature, the next step in the methodology was to define the sources of information to be applied, trying to limit the search to sources that would provide the most relevant information to the project objective.

For this task, databases from Tecnológico de Monterrey, Campus Monterrey were initially evaluated doing a preliminary search. As a result databases selected were:

- Datamonitor 360.

Country Statistics, Market Data Analytics, and Product Launch Analytics which also provides market, companies and industries analysis.

\section{- ISI Emerging Markets}

Company profiles, news, macroeconomic indicators, financial markets, industry behavior and reports which generally considered emerging countries, including Mexico.

\section{Initial Information Research}

Once it was defined the databases to be used for the project, an initial research of information was made in order to know the amount and quality of the information that could be obtained.

\section{Preliminary Evaluation}

These results allowed us to validate both the preliminary databases as the collection strategy applied. They were presented to the company "XYZ" to have an assessment of the information obtained. With this activity, we closed gaps between the company requirements and preliminary results, so it was possible to properly focus the efforts of the research. 
7. Final Project Scope Definition And Delimitation Of Key Concepts

Once we had concluded the initial assessment of information with the company "XYZ" it was agreed to limit the research on the specific market of "Styrenic Block Copolymers" emerging as the most attractive area to the company. Under this approach the following Key Intelligent Topics were selected:

- Thermoplastic Elastomers

- Styrene Block Copolymer

- Styrene-Butadiene-Styrene

- Styrene-Isoprene-Styrene

- Hydrogenated Styrenic Block Copolymers

\section{Information Research}

This process began with a collection in the database ISI Emerging Markets delimiting the searches from year 2009 to year 2012. In total 3600 results were obtained but many of them were not relevant for the project. An exploration in the database Datamonitor 360 was made with the same criteria obtaining about 550 results. In the next stage of the project, a segregation of items was made according to specific topics of interest for the company.

\section{Selection of relevant documents}

The initial information research resulted in about 4000 documents from both databases: ISI Emerging Markets and Datamonitor 360.

As many of these results were repeated and valueless for the research, it was necessary to do a selection of the most useful information. For this purpose a segregation of reports, news, and data was made considering particular research axes established by the company in terms of: materials, technologies, final products, and strategic actions (mergers, acquisitions, alliances, etc.).

10. Information analysis
Driving Forces Analysis technique proposed by Fleisher \& Bensoussan (2007) was applied in this stage. Driving Forces are elements with the capacity to change the industry structure. This tool was selected as it was the most suitable to get insights requested for the Company involved in the study.

\section{IC report development}

Once the analysis of the information found in the research was completed, the next step in the process was to develop a IC report with the main findings including recommendations established.

\section{Dissemination}

A personal presentation was made to the experts and decision makers at the company "XYZ" with the objective of disseminating the findings, conclusions, and recommendations developed.

\section{Validation of information}

During the application of the methodology different presentations of the results were made to the company "XYZ" in order to guide the research according to the main purpose established. Validation of information was made with experts from the company and with external people (industry and academy) maintaining confidentiality of information.

\section{Decision-making process}

The final stage of the methodology, the decision-making process is the job of the Senior Management of company "XYZ" as we delivered the recommendations of the CI report.

\section{Findings of the analysis}

As it was mentioned before the "Driving Forces Analysis" technique of Fleisher \& Bensoussan (2007) was applied during the analysis stage. An identification of the Driving Forces for the industry of Thermoplastics Elastomers was made 
according to: economic, social and technological factors. Here we present some interesting findings (for confidential reasons not all results could be shown):

\section{Economic Factors}

The economic factors of the Thermoplastic Elastomer industry, in specific SBC were divided into two important points. The first one was the up-to-date market situation including demand and consumption, and the second one was the industry's competitors.

\section{Market Condition}

After the recovery from the economic crisis of 2009, SBC consumption in all regions increased, although the rate of growth is slow due to per se market maturity. It is important to point out that the footwear market decline has affected most Western Europe. On the other hand, China has a growing demand in this industry but at a slower pace (Löchne \& Mori, 2011). The following Figure shows the percentage of world consumption of the different classifications of SBC:

\section{Global Consumption of SBC}

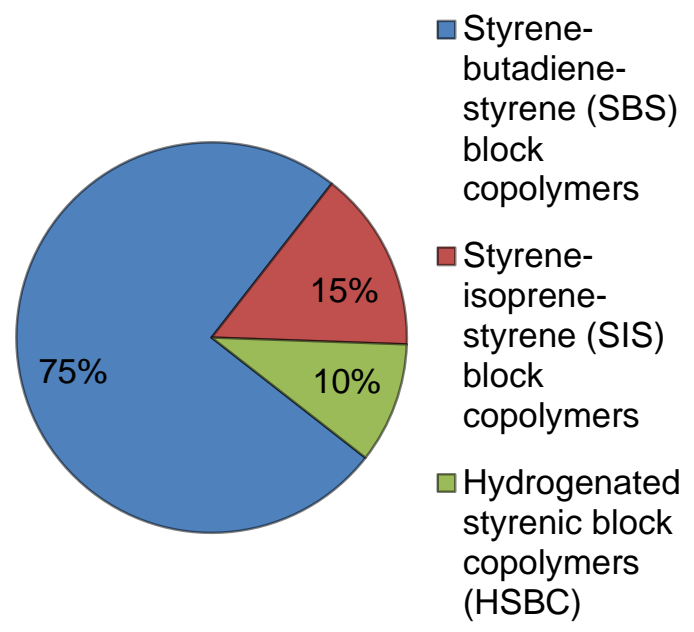

Figure 2: Distribution of global consumption by classification Styrenic Block Copolymers (Compiled from Zhang Li China National Petroleum and Chemical Plannino Institute 2011)
Currently, within the classifications of Styrenic Block Copolymers, the Styrene-ButadieneStyrene (SBS) is the highest category of consumption with a total of 75\% of SBC's market share, followed by Styrene-Isoprene-Styrene (SIS) with a consumption rate of $15 \%$, and Hydrogenated Styrenic Block Copolymers (HSBC) with a $10 \%$ share, according to Zhang Li China National Petroleum and Chemical Planning Institute (2011). The demand for the category of Hydrogenated Styrenic Block Copolymers (HSBC) which include StyreneEthylene/Butylene-Styrene (SEBS), StyreneEthylene/Propylene-Styrene (SEPS) and StyreneEthylene/Ethylene-Propylene-Styrene (SEEPS), is growing faster than other categories of SBC's, at rates of $8 \%$ to $10 \%$ in certain regions (Nandini Consultancy Center, 2011).

Moreover, it is expected that there will be an increment in global consumption of SBC to an average annual rate of about $4.5 \%$ during 2010 2015. In developed regions, consumption will be driven by the use of SBC for the market of adhesives and sealants. In Asia (excluding Japan) polymers and asphalt modified will drive consumption, as the growth rates for footwear has considerably decreased. On the other hand, Central and Eastern Europe have become an interesting market, the total demand growth is forecasted to be at $8-10 \%$ per year until 2015, developing even faster than in China (Löchne \& Mori, 2011).

\section{Styrenic Block Copolymers (SBC) Competitors}

Currently, $70 \%$ of the global production capacity of the SBC market is dominated by key players, in particular:

- Kraton Performance Polymers, Inc., United States of America.

- TSRC Corporation, Taiwan

- Lee Chang Yung, Taiwan

These companies play a key role in the industry due to their large investments in Asia, their manufacturing capacity, and current research on new developments related to Hydrogenated Styrenic Block Copolymer (HSBC). 
Recommendations

The first recommendation for the company "XYZ" is to invest more in Research and Development, mainly in the HSBC category but considering also: SEBS, SEPS, and SEEPS.

Secondly, it is important to carefully analyze the participation of the companies in China, because of the saturation of the market and the overcapacity of their plants up to $50 \%$ (Löchne \& Mori, 2011). For this reason they must consider other developing regions such as Eastern Europe.

Central and Eastern Europe represents an interesting opportunity to explore as their demand has interesting growth which is forecasted at 810\% per year until 2015 (Löchne \& Mori, 2011).

\section{Social Factors}

This section is divided into two major points. First: the SBC's relationship with the natural environment. Second: the involvement of the government in the industry.

Styrenic Block Copolymers and Environment

During the 12th Five-Year Development Guidelines for the Petroleum and Chemical Industry, one of the main issues that were analyzed was to strengthen the chemical sector on energy saving and environmental protection (Changjin, 2012). In this respect a significant trend in the industry of elastomers is one called "Green Technology". The case of Goodyear and its BioTRED technology in tires is a good example. Organic products replace conventional raw materials and the product gets the additional benefit of reduced friction and weight. It is clear that companies in the industry of SBC should not only pay attention to elements such as design, production and operation costs, but they should also follow changes in environmental regulations and pressure from customer groups, as these are demanding products that are more environmental friendly.

Regulations for Handling and Disposal in the industry Styrenic Block Copolymers
According to Changjin (2012), in recent years the Chemical and Petroleum Industry in China has increased concern about environmental issues related to energy consumption, recycling and pollution. China in fact, announced in early 2012 a plan to reduce emissions of carbon dioxide (CO2) by 2020 to a level of $40-45 \%$ lower than in 2005 , which would be the equivalent of saving 670 million metric tons of coal.

Recommendations

It is expected that international regulations become stricter regarding the environment, health, and security issues related to the industry of plastic and petroleum. A recommendation for the company "XYZ" is to develop a specific group to manage this issue, trying to anticipate changes in environmental laws. In particular it is important to detect any compound that could produce a negative effect on peoples' health.

\section{Technological Factors}

Development of New Products in the Industry Styrenic Block Copolymers

During the research one remarkable product we identified was $\mathrm{K}$ resin which is a synthetic resin with properties of transparency and high impact resistance. It is a product composed by a copolymer butadiene / styrene with a high content of styrene $(70-85 \%)$. It has a substantial potential in the medical and food package industry (Zhang Li China National Petroleum and Chemical Planning Institute, 2011). Moreover, applications that $\mathrm{K}$ resin can have are focused on elaborate food containers, packaging, medical devices, toys, footwear, and household appliances, among others.

It is important to remark that construction of production facilities of $\mathrm{K}$ resin in China is at an early stage. Units with a capacity of 25,000 tons have already been built. The consumption in China of $\mathrm{K}$ resin was for 50,000 tons in 2009. China's demand is mainly satisfied by imports as it can only produce locally $20 \%$ of its consumption (Zhang Li China National Petroleum and Chemical Planning Institute, 2011). It is 
expected that the demand in China for $\mathrm{K}$ resin reaches 80,000 tons in 2015 . This product has a an important market potential.

\section{Recommendations}

The company "XYZ" should integrate $\mathrm{K}$ resin into its business. According to Zhang Li China National Petroleum and Chemical Planning Institute (2011), this is the right time to exploit this product. The demand of $\mathrm{K}$ resin is anticipated to grow to 80,000 tons in 2015 , and the current capacity in China is not able to satisfy that requirement.

Finally, it would be interesting to conduct a deep benchmarking process of key competitor's like those mentioned before.

\section{Conclusions}

Through the application of a Competitive Intelligence methodology, it was possible to obtain valuable insights into the plastics industry. From the results obtained, it is clear that the industry of Styrenic Block Copolymers is currently growing to develop more specialized products. Innovations in adhesives, sealants, medical, and compounds applications are the most prominent areas of development.

The company "XYZ" should compete with a product differentiation strategy in these categories, rather than high-volume products (commodities) or low cost strategy. It is also important to combine the differentiation strategy with niche strategy, considering in particular the region of Eastern Europe which market is estimate to grow between 8 and $10 \%$ by 2015 . In addition, research and development efforts in the Styrenic Hydrogenated Block Copolymers (HSBC) represents an interesting opportunity to undertake, provided that the market will grow faster than the other categories of SBC's, at rates of $8 \%$ to $10 \%$. Finally the company should increase its efforts to be aware of environmental issues, for example it could strengthen its strategies to reduce $\mathrm{CO} 2$ emissions.

\section{References.}

Baregheh, A., Rowley, J., \& Sambrook, S. (2009). Towards a multidisciplinary definition of innovation. Management Decision , 13231339.

Bose, R. (2008). Competitive intelligence process and tools for intelligence analysis. Industrial Management \& Data Systems , 510-528.

Changjin, C. (2012). Gains and Pains in China's Chemical Industry in 2011. China Chemical Reporter, 5.

Fleisher, C. S., \& Bensoussan, B. E. (2007). Business and Competitive Analysis Effective Application of New and Classic Methods. New Jersey: FT Press.

Kahaner, L. (1997). Competitive Intelligence : How to Gather, Analyze, and Use Information to Move Your Business to the Top. New York: Toushstone.

Löchne, U., \& Mori, H. (2011). Styrenic Block Copolymers. IHS.

Murphy, C. (2005). Competitive Intelligence Gathering, Analysing and Putting it to work. Burlington: Gower Publishing Company.

Nandini Consultancy Center. (2011). STYRENIC BLOCK COPOLYMER (SBC) Insight and analysis for the chemical industry. Nandini Chemical Journal , 1-6.

Vega, J. R. (2010). Propuesta de integración de la Inteligencia Competitiva con la Innovación Abierta. Monterrey: ITESM.

Zhang Li China National Petroleum and Chemical Planning Institute. (2011). New Changes in Styrene Downstream Market Opportunities. China Chemical Reporter , 16-18. 